\title{
Changes in the composition of the spring zooplankton of Lake Baikal
}

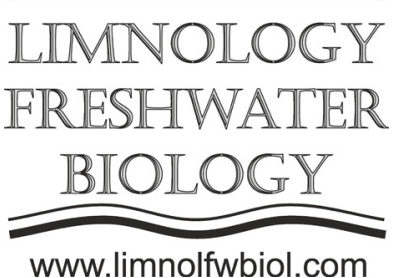

\author{
Naumova E.Yu.*, Troitskaya E.S., Zaidykov I.Yu. \\ Limnological Institute Siberian Branch of the Russian Academy of Sciences, Ulan-Batorskaja Str., 3, Irkutsk, 664033, Russia
}

\begin{abstract}
Since the 60s of the past century, researchers from Limnological Institute SB RAS have been regularly sampling zooplankton in a network of stationary stations along the Baikal water areas. In 2009-2018, the samples were collected in late May or early June immediately after the melting of ice during the complex expedition. The total biomass and abundance of zooplankton did not go beyond the interannual fluctuations observed in the 60-90s of the past century. A high abundance of spring rotifers in the Middle and Southern basins was also observed in 2015-2018. In the northern basin, the maximum rotifers indicator for the entire period of $30 \%$ of the plankton abundance was recorded only in 2016. The amount and composition of organisms in the surface layer depend on many factors. In our opinion, the depth and temperature characteristics of the water layer play an important role. The change in the heating and mixing of water could have led to observed shifts in the surface plankton composition.
\end{abstract}

Keywords: Baikal, zooplankton, pelagic zone, rotifers, temperature.

\section{Introduction}

Since the 60s of the past century, researchers from Limnological Institute SB RAS have been regularly sampling zooplankton in a network of stationary stations along the Baikal water areas. Such studies revealed patterns of macroscale distribution of zooplankton and trends in its interannual dynamics. Many researchers indicate the influence of global changes on the Baikal plankton (Afanasyeva and Shimaraev, 2006; Hampton et al., 2014; Izmest'eva et al., 2016). Indicators of spring zooplankton have long remained stable. However, the absolute and relative abundance of rotifers in the zooplankton of the Southern and Middle basins in 2014 exceeded the upper limits identified in previous years (Naumova and Zaidykov, 2018).

\section{Material and methods}

In 2009-2018, the samples were collected in late May or early June immediately after the melting of ice during the complex expedition of the research vessels "Akademik V.A. Koptyug" and "G.Yu. Vereshchagin". Data were used from three transects located in different basins of the lake. The extreme stations were located three kilometres from the shore. The Juday net was used with a diameter of $37 \mathrm{~cm}$ and a mesh size of a filtering cone of $88 \mu \mathrm{m}$, from the layers of $0-50 \mathrm{~m}$. Samples were calculated according to "Atlas..." (1995).

\section{Results and Discussion}

The total biomass and abundance of zooplankton did not go beyond the interannual fluctuations observed in the 60-90s of the past century. The total number of zooplankton in 2015-2018 fluctuated synchronously in three basins (Fig.). A high abundance of spring rotifers in the Middle and Southern basins was also observed in 2015-2018. In the northern basin, the maximum indicator of rotifers for the entire period of $30 \%$ of the plankton abundance was recorded only in 2016.

The amount and composition of organisms in the surface layer depend on many factors. In our opinion, the depth and temperature characteristics of the water layer play an important role. The change in the heating and mixing of water could lead to observed shifts in the surface plankton composition.

According to our data (Makarov et al., 2019), up to $50 \%$ of the biomass of mesozooplankton can be located deeper than $50 \mathrm{~m}$. Therefore, the sampling for scientific and environmental purposes must be carried out at Lake Baikal, taking into account these features.

\section{Acknowledgements}

This study was carried out within the project 0345-2019-0008 （AAAA-A16-116122110065-4) "Assessment and Forecast of Ecological State of Lake Baikal and Adjacent Territories under Conditions of 




Fig. The abundance (thous. specimens $/ \mathrm{m}^{3}$ ) of spring zooplankton in different basins of Lake Baikal (within the layer of 0-50 $\mathrm{m}$ )

Anthropogenic Impact and Climate Change" and by RFBR grant No. 19-07-00322a.

\section{References}

Afanasyeva E.L., Shimarayev M.N. 2006. Long-term change in zooplankton of the pelagic zone of Lake Baikal during the global climate change. In: Alimov A.F., Boulion V.V. (Eds.), Sostoyaniye i problemy produktsionnoy gidrobiologii [Status and problems of the productive hydrobiology]. Moscow, pp. 253-265. (in Russian)

Atlas i opredelitel' pelagobiontov Baikala (s kratkimi ocherkami po ikh ekologii) [Guide and key to pelagic animals of Baikal]. 1995. In: Timoshkin O.A., Mazepova G.F., Mel'nik N.G. et al. (Eds.). Novosibirsk: Nauka. (in Russian)
Hampton S.E., Gray D.K., Izmest'eva L.R. et al. 2014. The rise and fall of plankton: long-term changes in the vertical distribution of Algae and Grazers in Lake Baikal, Siberia. PLoS ONE 9. DOI: 10.1371/journal.pone.0088920

Izmest'eva L.R., Moore M.V., Hampton S.E. et al. 2016. Lake-wide physical and biological trends associated with warming in Lake Baikal. Journal of Great Lakes Research 42: 6-17. DOI: 10.1016/j.jglr.2015.11.006

Makarov M.M., Kucher K.M., NaumovaE.Yu. 2019. Vertical distribution of zooplankton after rapid change in temperature and chlorophyll concentration. Limnology and Freshwater Biology 2: 177-180. DOI: 10.31951/2658-3518-2019-A-1-177

Naumova E.Yu., Zaidykov I.Yu. 2018. Spring zooplankton of pelagial of the Baikal Lake. Hydrobiological Journal 54: 33-39. DOI: 10.1615/HydrobJ.v54.i1.30 